\title{
An Effective Application and Analysis Method based on User's Profiles in Elective Subjects
}

\author{
Rikeeta Mahajan $^{1}$, Prof. Priti Subramanium ${ }^{2}$ \\ ME, Computer Science, SSGBCOE, Bhusawal, India ${ }^{1}$ \\ Asst. Prof., Computer Science, SSGBCOE, Bhusawal, India ${ }^{2}$
}

\begin{abstract}
Every educational institute generates huge bulky data related to all the students getting education from the institute. Though much data produced may be worthless, the institute can use some valuable information to provide better education. Data mining can be employed for such purposes so that key knowledge can be extracted for future use. Difficulty arises for the engineering students when they reach the final year. They are made to choose electives as their subjects. Students may know nothing about what the knowledge the subject represent for. This may create choice for them as the electives have considerable values in the grading system too and if the student fails to choose the appropriate elective then it may affect the final grades. To eliminate this trouble, a beneficial system is planned to develop using fuzzy logic system (FLS). The main objective is to help the pupils select the right our electives in their final year of engineering and data mining concepts would be useful to gain key information about the students on the basis of which the proper elective can be pointed out.
\end{abstract}

Keywords: Final Grades, FLS, Elective Subject, Data Mining.

\section{INTRODUCTION}

Information from the transcripts of students are analyse, and using this information relationship is conducted between the respective courses and their elective subjects taken previously by the student. Rules are extracted with the help of data mining techniques and an elective subject suggestion system is implemented by using fuzzy logic. Successful results are obtained from the test; it is observed that the students successful from the respective courses are also successful in the related elective ones. It will be very productive and user friendly Application. To develop an android application for elective subject selection for students.

The purpose of this application is to guide students for final year elective subjects' election of all branches. Developing the web portal from which tests questionnaires can be updated and previous results can be updated. (Visible to teachers). Information from the transcripts of students are analysed, and using this information a relationship is conducted between the respective courses and their elective subjects taken previously by the student. Rules are extracted with the help of data mining techniques and an elective subject suggestion system is implemented by using fuzzy logic. Successful results are obtained from the test; it is observed that The students successful from the respective courses are also successful in the related elective ones. Motivation of this project is we have to choose elective subject with the help of college marks and university marks .In this project students easily find out his elective subject with the help of android application which is based on fuzzy logic. Using fuzzy logic imitates the way of decision making in humans that involves all intermediate possibilities between digital values YES and NO.

The fuzzy logic works on the levels of possibilities of input to achieve the definite output. It can be implemented in systems with various sizes and capabilities ranging from small micro-controllers to large, networked, workstationbased control systems. It can be implemented in hardware, software, or a combination of both.

It can be implemented in systems with various sizes and capabilities ranging from small micro-controllers to large, networked, workstation-based control systems. It can be implemented in hardware, software, or a combination of both.

\section{ALGORITHM}

\section{A) C4.5 Algorithm}

C4.5 is collection of algorithms for performing classifications in machine learning and data mining. It develops the classification model as a decision tree. C4.5 consists of three groups of algorithm: C4.5, C4.5-no-pruning and C4.5rules. In this summary, we will focus on the basic $\mathrm{C} 4.5$ algorithm.C4.5 is an algorithm used to generate a decision tree. C4.5 is an extension of Quintans earlier ID3 algorithm. The decision trees generated by C4.5 can be used for classification and for this reason; it is often referred to as a statistical classifier.

Input:-An attribute value data set $\mathrm{D}$ 
1. Tree $=$ If $\mathrm{D}$ is pure OR other stopping criteria met then

2. Terminate.

3. $\quad$ End if

4. for all attributes

5. Compute information theoretic criteria if we split on a.

6. $\quad$ End for

7. Abest =best attribute according to above computed criteria.

8. Tree $=$ Create a decision node that tests abest in the root.

9. $\mathrm{Dv}=$ Induced sub-datasets from $\mathrm{D}$ based on abest.

10. for all Dv do

11. Treev $=\mathrm{C} 4.5(\mathrm{Dv})$

12. Attach TREEV to the corresponding branch of tree.

13. End for.

14. Return tree.

Tests are possible not only binary, but also n-ary branches/outcomes are supported by C4.5.Test are chosen by Information-theoretic criteria such as gain and gain ratio are used to determine the best test greedily. Test threshold are chosen for nominal attribute, it is straightforward i.e. different possible instantiations of that attribute. For numeric attributes, the threshold is chosen by sorting the attribute values, and chooses a split between successive values that maximize the information-theoretic criteria. Not all splits between successive values need to be problem of prediction of final grades students receives on completing university courses is able to deliver good solutions. To apply ACO in any recommender system we need special problem representation in form of a graph, where each node represents a decision in the problem domain.

\section{SPECIFICATION AN D TECHNOLOGY}

A) Technical and functional specifications for projects:-

- Assist in determining time and cost estimates for assigned projects.

- Develop new applications or make enhancements according to project needs.

- Utilize programming principles, tools, and techniques to write application codes.

- Plan, coordinate and execute project activities to ensure timely completion.

- Ensure project deliverables meet business requirements.

- Prepare test cases and strategies for unit testing and integration testing.

- Perform code reviews to identify basic technical and logical errors.

- Resolve application development issues in a timely manner - Manage project risks, and milestones.

- Develop best practices to improve productivity.

B) Front End Technology:

\section{1) Android:-}

Android is a mobile operating system developed by Google, based on the Linux kernel and designed primarily for touch screen mobile devices such as smart phones and tablets. Android's user interface is mainly based on direct manipulation, using touch gestures that loosely correspond to real-world actions, such as swiping, tapping and pinching, to manipulate on-screen objects, along with a virtual keyboard for text input. Android has the largest installed base of all operating systems (OS) of any kind. Android oriented smart phones can use this application efficiently. Useful for students and teachers to determine the elective subject details of every branch. Any institute providing education in engineering field can utilize this application for facilitating better guidance with accordance to the student's skills. The front end technology being used will be Android. Android was released under the Apache v2 open source license. Android is an open source mobile operating system developed by Google and Open Handset Alliance (OHA). It is mainly designed for mobile phones with the touch screen facility such as Smart phones and tablets. The user interface in Android basically depends on direct manipulation. This is done either by touch gestures which are associated with actions like tapping, pinching, sliding, etc. for manipulating objects on the screen with the help of virtual keyboard. It is a widespread technology with a low cost, customizable, readymade operating system for devices with high technology.

\section{C) Back End Technology:-}

1) Microsoft Visual Studio 2012 (For Web Services):

It is an integrated development environment (IDE) from Microsoft. Visual Basic Express 2012 has many new features than earlier version of VB. It is used to develop computer programs for Microsoft Windows, as well as web sites, web 
apps, web services and mobile apps. Visual Studio 2012 includes support for new project templates for building Metro UI apps for multiple devices.

\section{2) Windows Server 2012 R2 (For Database):}

The back end technology will be SQL server 2012 R2. It is a server operating system produced by Microsoft. Windows Server 2012 R2 supports up to 64 physical processors or up to 256 logical processors per system. SQL Server Management Studio is an integrated environment for accessing, configuring, managing, and administering all components of SQL Server. Microsoft SQL Server 2012 R2 will provide support for geospatial visualization including mapping, routing, and custom shapes. SQL Server 2012 R2 provides lot many new features and capabilities for Business Intelligence users which can be leveraged by many organizations around the world.

\section{TESTING AND RESULTS}

A)Unit testing:-It is use to check the execution path of the module, function and procedure of the system. Test is conducted with the help of normal data and abnormal data. This testing includes the different factors like coverage, processing and statement coverage, branch loop abnormality, circulation etc. With the help of this unit testing we check that all the statement in the code is executed or not so it avoids the dead code statement. It checks all the branches and executing path of the code. It insures that all internal method of program are executed and properly integrated with program. After the coding step we do the unit test for project in this test we check the project as unit wise. Full project is dividing into number of modules so we check every module separately in this testing we use driver and stub mainly for testing. Driver and stub are the software. In the application program driver is only as a main program and stub is stub serve to replace modules that are subordinate the component to be tested.

Using unit Testing for student module following result found which shown in figure 1

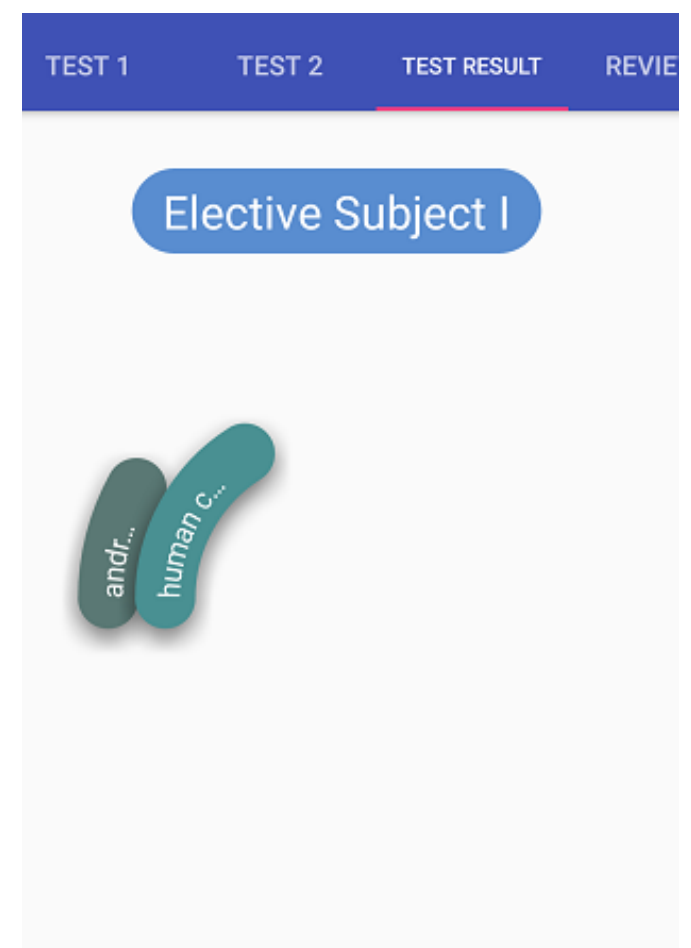

Figure 1.Elective subject Result

\section{B) Integrated Testing:-}

In the integrated testing, all the modules are check together to insure that all the modules are executing together according to program specification. Once all the modules have been tested in divisionally, the most legitimate question can be asked is that when all the modules are working properly, why there we need have integrated testing? The answer is, throw all modules are working properly problem may occurs while interfacing individual module. Data can loss across an interface and one module can have an adverse effect on another. Integrated testing is done on dummy data and the with actual data.

Using integration testing on student and admin module got college and university marks analysis graph as sohown in figure 2 and figure 3 


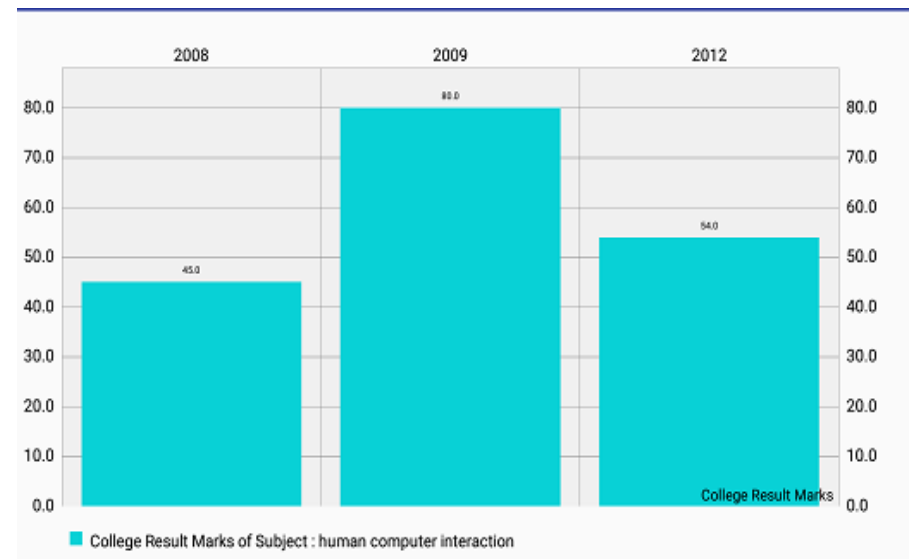

Figure 2. Elective subject college result analysis

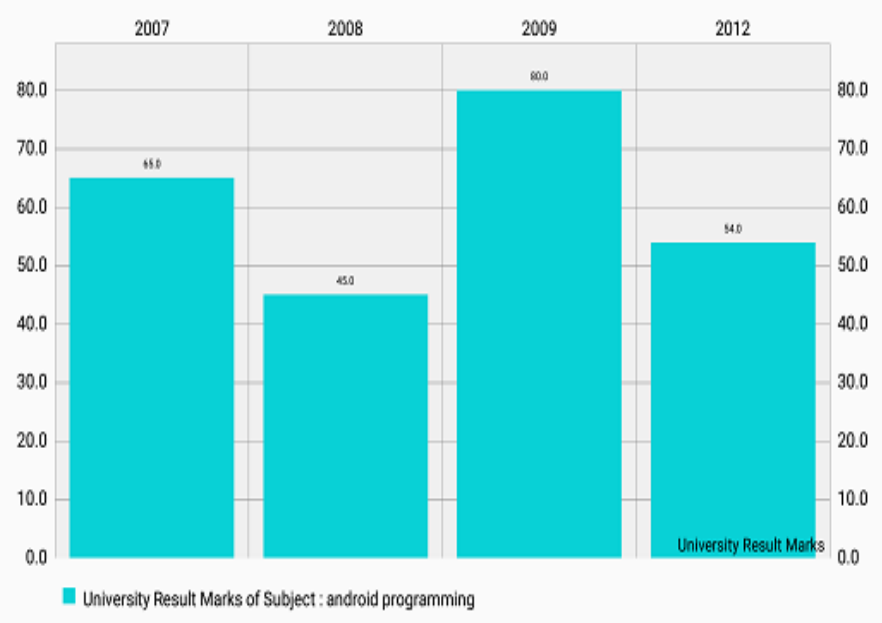

Figure 3.Elective subject university result analysis

\section{CONCLUSION}

In this paper we have empirically studied the fuzzy logic decision tree model for software cost estimation. The result shows that combining fuzzy logic and the decision tree model improves greatly the accuracy of estimates. In our system, we found that proper utilization of pruning confidence factor and fuzziness control threshold has shown an increase of estimation accuracy. Therefore, several values for the models parameters like subject test result, college last year result as well as university result must be evaluated when building fuzzy decision tree for software cost estimation to find appropriate elective subject for the study in college.

\section{REFERENCES}

[1] Yager R. R., Fuzzy logic methods in recommender systems, Fuzzy Sets and Systems, 136, (2003), 133 -149.

[2] Kreber C., The relationship between students' course perception and their approaches to studying in undergraduate science courses: a Canadian experience, 22/1, 57-76, 2003.

[3] Mironova O., Amitan I., Vilipold, J., Saar, M., Ruutmann T., Computer science e-courses for students with different learning styles, 2013 Federated Conference on Computer Science and Information Systems, 8-11 Sept, 2013, 735-738.

[4] Fertalj K., Bozic N.H., Jerkovic H., The integration of learning object repositories and learning management systems, Computer Science and Information Systems, Vol. 7, No. 3, 387-407. (2010)

[5] Astin A. W., Sax L. J., How undergraduates are affected by service participation, Journal of College Student Development, 39 , $1998,251-253$.

[6] Kristiansen S., Sorensen M., Stidsen T. R., Elective course planning, European Journal of Operational Research, 215, (2011), 713-720.

[7] Paquette E., Computer Graphics education in different curricula: analysis and proposal for courses, Computers Graphics, 29 , (2005), 245-255.

[8] Klasnja-Milicevic A., Vesin B., Ivanovic M., Budimac Z., E-Learning personalization based on hybrid recommendation strategy and learning style identification, Computers \& Education, 56, (2011), 885-899. 